Research Paper

\title{
The clinical significance of preoperative serum cholesterol and high-density lipoprotein-cholesterol levels in hepatocellular carcinoma
}

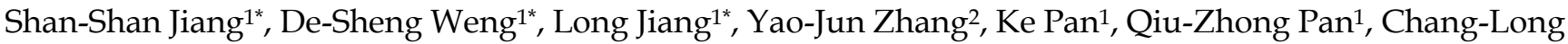 \\ Chen ${ }^{1}$, Jing-Jing Zhao', Xiao-Fei Zhang ${ }^{1}$, Hong-Xia Zhang1, Yan Tang1, Zi-Qi Zhou1, Min-Shan Chen², \\ Jian-Chuan Xia ${ }^{\boxplus}$ \\ 1. Sun Yat-sen University Cancer Center; State Key Laboratory of Oncology in South China; Collaborative Innovation Center for Cancer Medicine, Guangzhou \\ 510060, China; \\ 2. Department of Hepatobiliary Oncology, Sun Yat-sen University Cancer Center, Guangzhou, People's Republic of China. \\ *Shan-Shan Jiang, De-Sheng Weng and Long Jiang contributed equally to this work
}

$\square$ Corresponding author: Jian-Chuan Xia, Sun Yat-sen University Cancer Center, 651 Dongfeng Road East, Guangzhou 510060, P. R. China. Address: State Key Laboratory of Oncology in Southern China and Department of Experimental Research, Sun Yat-sen University Cancer Center, 651 Dongfeng Road East, Guangzhou 510060, P. R. China. Tel.: +86-20-87343173 Fax: +86-20-87343392 Email: xiajch@mail.sysu.edu.cn.

(1) Ivyspring International Publisher. Reproduction is permitted for personal, noncommercial use, provided that the article is in whole, unmodified, and properly cited. See http://ivyspring.com/terms for terms and conditions.

Received: 2015.09.13; Accepted: 2016.01.22; Published: 2016.03.20

\begin{abstract}
Purpose: To evaluate the prognostic role of the preoperative plasma lipid profile, including low-density lipoprotein -cholesterol [LDL-C], high-density lipoprotein-cholesterol [HDL-C], cholesterol, and triglycerides, in hepatocellular carcinoma patients undergoing radical resection.

Methods: Clinical data, including the preoperative plasma profile levels, were retrospectively collected and reviewed in 1411 hepatocellular carcinoma patients, who underwent operation between 2001 and 2010. Kaplan-Meier method and the Cox proportional hazards regression model were used in analyzing the DFS and OS.

Results: We found that HDL-C $\leq 0.88 \mathrm{mmol} / \mathrm{L}$ and cholesterol $\leq 4.420 \mathrm{mmol} / \mathrm{L}$ were preoperative risk factors of disease-free survival (DFS) and overall survival (OS). A decreased $\mathrm{CHO}$ level was significantly associated with decreased OS (HR, 0.800; $95 \% \mathrm{Cl},(0.691-0.926), \mathrm{P}=0.003)$ and decreased DFS (HR, 0.844; $95 \% \mathrm{Cl}, 0.737-0.966, \mathrm{P}=0.012)$. Additionally, an increased HDL-C level was shown significant association with increased OS (HR, $0.679 ; 95 \% \mathrm{Cl}, 0.570-0.808, \mathrm{P}<0.01)$ and DFS (HR, 2.085; 95\% Cl, 1.271- 3.422, $\mathrm{P}=0.002$ ). In the univariate and multivariate analyses involving OS and DFS, no significant relativity were observed between the LDL-C and TG groups. Conclusions: Decreased levels of CHO and HDL might predict worse outcomes both DFS and OS for hepatocellular carcinoma patients.
\end{abstract}

Key words: cholesterol, high-density lipoprotein-cholesterol, hepatocellular carcinoma, prognosis.

\section{Introduction}

Hepatocellular carcinoma (HCC), with estimated 782,000 new cases global incidence every year, caused nearly 746,000 deaths worldwide annually [1]. However, the high risk of metastasis and recurrence after operation for patients with HCC is high [2-3]. The high rate of recurrence after complete resection is a significant prognostic factor, with a cumulative recurrence rate of $50 \%$ and $60 \%$ at 3 years and $60 \%$ and $80 \%$ at 5 years [4-7]. To date, a variety of predictive biomarkers have been shown to predict clinical outcomes in HCC patients. For example, Chuma $M$ found that HSP70 could be a sensitive indicator for the differential diagnosis of early HCC from precancerous lesions or noncancerous livers [8]. 
In addition, Jiang suggested the possible oncogenic and prognostic role of Galectin-3 in hepatocellular carcinoma [9]. Due to complicated detective equipment and expensive costs, accurate, fast, as well as convenient predictive biomarkers for the identification of patients with high risk of metastasis and recurrence are urgently needed.

Abnormal lipid metabolism is considered to be related to several cancers [10]. In previous research, reduced pre-operative HDL-C levels were linked with poor survival in NSCLC patients [11]. Additionally, low HDL-C levels are also associated with increased post-menopausal breast cancer risk [12-15]. However, the role of lipid metabolism in cancer development has not been fully explored. Some recent studies have illustrated the plasma lipid profiles of hepatocellular carcinoma patients: Ahaneku et al [16] found that in HCC patients, HDL-fraction levels, including HDL-phospholipids (HDL-PL), HDL-cholesterol (HDL-C) and the ratio of HDL-C/HDL-PL, in HCC patients were significantly lower than controls. Motta et al [17] recruited $40 \mathrm{HCC}$ patients, and evaluated their LDL-C and HDL-C levels. In HCC patients, the LDL-C levels were significantly lower than controls, but the HDL-C levels were not statistically significantly different from those of the controls. Chen $X$ et al [18] reported that there was a significant difference between high and low levels of serum TC that could be used to evaluate pancreatic carcinoma risk in Europeans. However, there is little evidence about the impact on lipid profiles in clinical outcomes with hepatocellular carcinoma patients.

The current study aimed to explore the predictive role of the lipid profile on overall survival (OS) and disease-free-survival (DFS) in HCC patients undergone complete resections.

\section{Methods}

\section{Patient Selection}

A total of 1411 HCC patients who had undergone complete surgical resection at Sun Yat-sen University Cancer Center from 2001 to 2010 were collected and reviewed in the present study. Approval was obtained from the Ethics Committee of the Sun Yat-sen University Cancer Center (Guangdong, China). Written informed consent was received from each patient. All patients met the following eligibility criteria: (1) all patients had pathologically confirmed hepatocellular carcinoma; (2) without cancer history; (3) no treatment before serum obtained; and (4) serum samples were collected before treatment, and the levels of LDL-C, HDL-C, TG, and CHO were tested using a Hitachi 7600-020 automatic biochemical analyzer. Clinical data, including the treatment strategy and the pathologically diagnosis, were obtained from the patients' records. For the current study, all pathological diagnoses were confirmed by an independent experienced pathologist at Sun Yat-sen University Cancer Center. Histological types were determined from the World Health Organization classification criteria.

\section{Patient follow-up}

All patients were followed-up in the outpatient department, and underwent physical examinations and laboratory tests every 3 months in the first 2 years, then every 6 months in the 3rd to 5 th years, and every year for an extra 5 years or death, no matter which occurred first. The primary outcome of the present study was overall survival (OS), defined as the time from curative resection to the time of death. Relatively, the secondary outcome was disease-free survival (DFS), calculated from the date of radical operation to the date of disease recurrence or distant metastases diagnosed.

\section{Statistical analysis}

The cut-off value of the lipid profile was established by receiver operating characteristic (ROC) curve statistical analyses. The Kaplan-Meier method and the log-rank test were used to calculate the survival curves. The risk factors for survival were identified by the Cox proportional hazards model. The associations between $\mathrm{CHO}$, HDL-C levels and clinic pathological parameters were tested by chi-square test. $P$ Values of less than 0.05 were considered statistical significant in all statistical approaches. Data analyses were performed with SPSS 18.0 (PASW Statistics 18) for Windows (SPSS Inc., Chicago, IL).

\section{Results}

\section{Patient Characteristics}

After the eligibility review, 1411 HCC patients who underwent radical surgical resection were enrolled in the analysis, and their characteristics are presented in Table 1. The median follow-up time was 79 months (range: 1 to 176 months). The median age at resection was 41 years (range: 5 to 78 years), and 1243 $(88.1 \%)$ of the patients were males and $68(11.9 \%)$ were females. Staging was conducted according to the tumor-node -metastasis (TNM) classification for HCC (Union for International Cancer Control). 848 patients $(60.1 \%)$ were diagnosed with stage I disease, other 563 (39.9\%) patients were diagnosed with stage II-III disease. A total of 1231 patients (87.2\%) had hepatic B virus infection. 
Table 1. Characteristics of patients.

\begin{tabular}{|c|c|c|}
\hline Characteristics & Patients & $\%$ \\
\hline \multicolumn{3}{|l|}{ Age } \\
\hline$\leq 50$ & 784 & 55.6 \\
\hline$>50$ & 627 & 44.4 \\
\hline \multicolumn{3}{|l|}{ Gender } \\
\hline Female & 68 & 11.9 \\
\hline Male & 1243 & 88.1 \\
\hline \multicolumn{3}{|l|}{ Tumor size } \\
\hline$\leq 5 \mathrm{~cm}$ & 543 & 38.5 \\
\hline$>5 \mathrm{~cm}$ & 868 & 61.5 \\
\hline \multicolumn{3}{|l|}{ HBsAg } \\
\hline Negative & 179 & 12.7 \\
\hline Positive & 1231 & 87.2 \\
\hline \multicolumn{3}{|l|}{ Cirrhosis } \\
\hline $\mathrm{NO}$ & 497 & 35.2 \\
\hline Yes & 914 & 64.8 \\
\hline \multicolumn{3}{|l|}{$\operatorname{AFP}(\mathrm{ng} / \mathrm{ml})$} \\
\hline$\leq 20$ & 422 & 29.9 \\
\hline$>20$ & 989 & 70.1 \\
\hline \multicolumn{3}{|l|}{ Tumor number } \\
\hline Single & 1113 & 78.9 \\
\hline Multiple & 298 & 21.1 \\
\hline \multicolumn{3}{|c|}{ Tumor differentiation } \\
\hline I-II & 1169 & 82.8 \\
\hline III-IV & 242 & 17.2 \\
\hline \multicolumn{3}{|l|}{ TNM stage } \\
\hline I & 848 & 60.1 \\
\hline II-III & 563 & 39.9 \\
\hline \multicolumn{3}{|l|}{ BCLC stage } \\
\hline O-A & 527 & 37.3 \\
\hline $\mathrm{B}-\mathrm{C}$ & 884 & 62.7 \\
\hline \multicolumn{3}{|l|}{$\mathrm{CHO}(\mathrm{mmol} / \mathrm{L})$} \\
\hline$\leq 4.42$ & 520 & 36.9 \\
\hline$>4.42$ & 891 & 63.1 \\
\hline \multicolumn{3}{|l|}{$\mathrm{TG}(\mathrm{mmol} / \mathrm{L})$} \\
\hline$\leq 1.06$ & 804 & 57 \\
\hline$>1.06$ & 607 & 43 \\
\hline \multicolumn{3}{|l|}{$\mathrm{LDL}(\mathrm{mmol} / \mathrm{L})$} \\
\hline$\leq 3.09$ & 701 & 49.7 \\
\hline$>3.09$ & 710 & 50.3 \\
\hline \multicolumn{3}{|l|}{ HDL (mmol/L) } \\
\hline$\leq 0.88$ & 256 & 18.1 \\
\hline$>0.88$ & 1155 & 81.9 \\
\hline
\end{tabular}

\section{Cut-off determination of lipid metabolism}

After receiver operating curve (ROC) analysis, the optimal cutoff value for $\mathrm{CHO}$ was $4.420 \mathrm{mmol} / \mathrm{L}$ (AUC: $0.532 \mathrm{mmol} / \mathrm{L}, 95 \% \mathrm{CI}: 0.502-0.562$ ), 1.06 $\mathrm{mmol} / \mathrm{L}$ for TG (AUC: $0.537 \mathrm{mmol} / \mathrm{L}, 95 \% \mathrm{CI}$ : 0.507-0.567), $0.88 \mathrm{mmol} / \mathrm{L}$ for HDL (AUC: 0.542 $\mathrm{mmol} / \mathrm{L}, 95 \% \mathrm{CI}: 0.512-0.572)$, and $3.09 \mathrm{mmol} / \mathrm{L}$ for LDL (AUC: $0.501,95 \%$ CI: $0.471-0.532$ ).

\section{The Correlation Between the CHO, HDL-C Levels and Other Clinical Characteristics}

The relationships between the clinicopathological features of HCC and $\mathrm{CHO}$ and HDL-C levels are summarized in Tables 2 and 3 . The statistical analysis showed that the $\mathrm{CHO}$ level was significantly related with cirrhosis $(\mathrm{P}=0.047)$. However, there was no significant links between
CHO levels and other clinicopathological parameters, including differentiation status, TNM stage, and BCLC stage (both $\mathrm{P}>0.05$ ). The HDL-C level was significantly correlated with tumor size $(\mathrm{P}<0.001)$, HBsAg $(\mathrm{P}=0.029)$, and BCLC stage $(<0.001)$.

Table 2. Relationship between $\mathrm{CHO}$ Concentration and Clinical Characteristics in 1411 Patients With liver cancer.

\begin{tabular}{|c|c|c|c|}
\hline Characteristics & $\mathrm{CHO} \leq 4.420$ & $\mathrm{CHO}>4.420$ & $\mathrm{P}$ \\
\hline Age & & & 0.147 \\
\hline$\leq 50$ & 302 & 482 & \\
\hline$>50$ & 218 & 409 & \\
\hline Gender & & & 0.239 \\
\hline Female & 55 & 113 & \\
\hline Male & 465 & 778 & \\
\hline Tumor size & & & 0.357 \\
\hline$\leq 5 \mathrm{~cm}$ & 192 & 351 & \\
\hline$>5 \mathrm{~cm}$ & 328 & 540 & \\
\hline HBsAg & & & 0.621 \\
\hline Negative & 69 & 110 & \\
\hline Positive & 451 & 780 & \\
\hline Cirrhosis & & & 0.047 \\
\hline $\mathrm{NO}$ & 166 & 331 & \\
\hline Yes & 354 & 560 & \\
\hline $\operatorname{AFP}(\mathrm{ng} / \mathrm{ml})$ & & & 0.104 \\
\hline$\leq 20$ & 169 & 253 & \\
\hline$>20$ & 351 & 638 & \\
\hline Tumor number & & & 0.286 \\
\hline Single & 402 & 711 & \\
\hline Multiple & 118 & 180 & \\
\hline $\begin{array}{l}\text { Tumor } \\
\text { differentiation }\end{array}$ & & & 0.059 \\
\hline I-II & 422 & 743 & \\
\hline III-IV & 98 & 148 & \\
\hline TNM stage & & & 0.463 \\
\hline I & 306 & 542 & \\
\hline II-III & 214 & 349 & \\
\hline BCLC stage & & & 0.349 \\
\hline $\mathrm{O}-\mathrm{A}$ & 186 & 341 & \\
\hline $\mathrm{B}-\mathrm{C}$ & 334 & 550 & \\
\hline
\end{tabular}

\section{The Prognostic Significance of Clinical Characteristics in Hepatocellular carcinoma}

In univariate analyses, significant correlation between tumor number, size, AFP, tumor differentiation, TNM stage, BCLC stage, $\mathrm{CHO}$ and HDL-C levels and DFS and OS were detected. In multivariate analysis, we observed significant associations of tumor size, AFP, TNM stage, $\mathrm{CHO}$, and HDL-C levels with OS (Table 4). In addition, associations between tumor size, AFP, TNM stage and CHO levels with DFS were observed. The multivariate analysis was conducted based on age at resection, gender, $\mathrm{HBsAg}$, gender, cirrhosis, AFP, tumor differentiation, tumor number, tumor size, TNM stage, BCLC stage, HDL-C level, CHO level, LDL-C level and TG level. 
Table 3. Relationship Between HDL Concentration and Clinical Characteristics in 1411 Patients With liver cancer.

\begin{tabular}{|c|c|c|c|}
\hline Characteristics & HDL-C $\leq 0.88$ & HDL-C $>0.88$ & $\mathrm{P}$ \\
\hline Age & & & 0.385 \\
\hline$\leq 50$ & 136 & 648 & \\
\hline$>50$ & 120 & 507 & \\
\hline Gender & & & 0.111 \\
\hline Female & 23 & 145 & \\
\hline Male & 233 & 1010 & \\
\hline Tumor size & & & $<0.001$ \\
\hline$\leq 5 \mathrm{~cm}$ & 62 & 481 & \\
\hline$>5 \mathrm{~cm}$ & 194 & 674 & \\
\hline HBsAg & & & 0.029 \\
\hline Negative & 43 & 136 & \\
\hline Positive & 213 & 1019 & \\
\hline Cirrhosis & & & 0.546 \\
\hline NO & 86 & 411 & \\
\hline Yes & 170 & 744 & \\
\hline $\operatorname{AFP}(\mathrm{ng} / \mathrm{ml})$ & & & 0.262 \\
\hline$\leq 20$ & 84 & 338 & \\
\hline$>20$ & 172 & 817 & \\
\hline Tumor number & & & 0.506 \\
\hline Single & 198 & 915 & \\
\hline Multiple & 58 & 240 & \\
\hline $\begin{array}{l}\text { Tumor } \\
\text { differentiation }\end{array}$ & & & 0.180 \\
\hline I-II & 204 & 961 & \\
\hline III-IV & 52 & 194 & \\
\hline \multicolumn{4}{|l|}{ TNM stage } \\
\hline I & 140 & 707 & 0.054 \\
\hline II-III & 116 & 448 & \\
\hline BCLC stage & & & $<0.001$ \\
\hline $\mathrm{O}-\mathrm{A}$ & 59 & 467 & \\
\hline B-C & 197 & 688 & \\
\hline
\end{tabular}

The Prognostic Significance of the Serum Lipid Profile in Hepatocellular carcinoma

Among the 1411 patients, distant metastasis or local recurrence after a radical surgical resection was diagnosed in 345 of $520(66.3 \%)$ patients with a $\mathrm{CHO}$ level $\leq 4.420 \mathrm{mmol} / \mathrm{L}$ and in 545 of $891(61.2 \%)$ patients with a CHO level $>4.420 \mathrm{mmol} / \mathrm{L}(\mathrm{P}=0.012)$. Regarding OS, there were 300 of 520 (57.7\%) patients with a CHO level $\leq 4.420 \mathrm{mmol} / \mathrm{L}$, and 449 of 891 $(50.4 \%)$ patients with a $\mathrm{CHO}$ level $>4.420 \mathrm{mmol} / \mathrm{L}$ $(\mathrm{P}=0.003)$ who occurred death. A decreased $\mathrm{CHO}$ level was significantly correlated with decreased OS (HR, 0.800; 95\% CI, (0.691-0.926), $\mathrm{P}=0.003$; Table 4; Figure 1) and remained statistically different in multivariate analysis including tumor size, AFP, tumor differentiation, and TNM stage (HR, 0.831; 95\% CI, 0.714-0.967, $\mathrm{P}=0.017$; Table 4). Patients with $\mathrm{CHO}$ levels $\leq 4.420 \mathrm{mmol} / \mathrm{L}$ presented with $\mathrm{OS}$ of 42 months. Conversely, patients with $\mathrm{CHO}$ level $>4.420$ mmol/L presented with OS of 62 months. In univariate analysis, a decreased $\mathrm{CHO}$ level was significantly linked with decreased DFS (HR, 0.844; 95\% CI, 0.737-0.966, $\mathrm{P}=0.012$ ) (Table 5; Figure 2) and remained statistically different in multivariate analysis including tumor size, AFP, tumor differentiation, and TNM stage (HR, 0.850; 95\% CI,
0.740-0.977, $\mathrm{P}=0.022$ ) (Table 5). Patients with $\mathrm{CHO}$ levels $\leq 4.420 \mathrm{mmol} / \mathrm{L}$ had a median DFS of 19 months. In a contrast patients with $\mathrm{CHO}$ levels $>4.420$ $\mathrm{mmol} / \mathrm{L}$ presented with a median DFS of 26 months.

Table 4. Univariate and Multivariate Cox Proportional Analysis with Overall Survival.

\begin{tabular}{|c|c|c|c|c|}
\hline \multirow{2}{*}{ Parameter } & \multicolumn{2}{|c|}{ Univariate Analysis } & \multicolumn{2}{|c|}{ Multivariate Analysis } \\
\hline & HR (95\% CI) & $\mathrm{P}$ & HR $(95 \%$ CI) & $\mathrm{P}$ \\
\hline Age & $1.086(0.941-1.254)$ & 0.258 & & \\
\hline \multicolumn{5}{|c|}{ (1) } \\
\hline \multicolumn{5}{|l|}{$>50$} \\
\hline Gender & $1.112(0.885-1.398)$ & 0.360 & & \\
\hline \multicolumn{5}{|l|}{ Female } \\
\hline \multicolumn{5}{|l|}{ Male } \\
\hline $\begin{array}{l}\text { Tumor size } \\
\leq 50\end{array}$ & \multicolumn{4}{|c|}{$\leq 50$} \\
\hline \multicolumn{5}{|l|}{$>5 \mathrm{~cm}$} \\
\hline HBsAg & $1.145(0.917-1.430)$ & 0.233 & & \\
\hline \multicolumn{5}{|l|}{ Negative } \\
\hline \multicolumn{5}{|l|}{ Positive } \\
\hline Cirrhosis & $1.057(0.908-1.230)$ & 0.475 & & \\
\hline \multicolumn{5}{|l|}{ NO } \\
\hline \multicolumn{5}{|l|}{ Yes } \\
\hline $\mathrm{AFP}(\mathrm{ng} / \mathrm{ml})$ & $1.833(1.545-2.174)$ & $<0.001$ & $1.632(1.372-1.941)$ & $<0.001$ \\
\hline \multicolumn{5}{|l|}{$\leq 20$} \\
\hline \multicolumn{5}{|l|}{$>20$} \\
\hline Tumor number & $1.990(1.696-2.334)$ & $<0.001$ & & \\
\hline \multicolumn{5}{|l|}{ Single } \\
\hline \multicolumn{5}{|l|}{ Multiple } \\
\hline $\begin{array}{l}\text { Tumor } \\
\text { differentiation }\end{array}$ & $1.514(1.266-1.810)$ & $<0.001$ & $1.250(1.042-1.499)$ & 0.016 \\
\hline \multicolumn{5}{|l|}{ I-II } \\
\hline \multicolumn{5}{|l|}{ III-IV } \\
\hline $\begin{array}{l}\text { TNM stage } \\
\text { I }\end{array}$ & \multicolumn{4}{|c|}{ I } \\
\hline \multicolumn{5}{|l|}{ II-III } \\
\hline BCLC stage & $2.052(1.749-2.408)$ & $<0.001$ & & \\
\hline \multicolumn{5}{|l|}{$\mathrm{O}-\mathrm{A}$} \\
\hline \multicolumn{5}{|l|}{ B-C } \\
\hline $\mathrm{CHO}(\mathrm{mmol} / \mathrm{L})$ & $0.800(0.691-0.926)$ & 0.003 & $0.831(0.714-0.967)$ & 0.017 \\
\hline \multicolumn{5}{|l|}{$\leq 4.42$} \\
\hline \multicolumn{5}{|l|}{$>4.42$} \\
\hline TG $(\mathrm{mmol} / \mathrm{L})$ & $0.908(0.785-1.049)$ & 0.588 & & \\
\hline \multicolumn{5}{|l|}{$\leq 1.06$} \\
\hline$>1.06$ & & & & \\
\hline $\begin{array}{l}\text { LDL } \\
\leq 3.09\end{array}$ & $0.936(0.811-1.080)$ & 0.364 & & \\
\hline$>3.09$ & & & & \\
\hline HDL & $0.679(0.570-0.808)$ & $<0.001$ & $0.790(0.658-0.948)$ & 0.011 \\
\hline$\leq 0.88$ & & & & \\
\hline$>0.88$ & & & & \\
\hline
\end{tabular}

Local recurrence or distant metastasis after radical surgical resection was confirmed in 176 of 256 (68.7\%) patients with an HDL-C level $\leq 0.88 \mathrm{mmol} / \mathrm{L}$ and in 714 of $1155(61.8 \%)$ patients with an HDL-C level $>0.88 \mathrm{mmol} / \mathrm{L}(\mathrm{P}=0.002)$. Regarding $\mathrm{OS}$, there were 161 of $256(62.9 \%)$ patients with an HDL-C level $\leq 0.88 \mathrm{mmol} / \mathrm{L}$, and 588 of 1155 (53.1\%) patients with HDL-C levels $>0.88 \mathrm{mmol} / \mathrm{L}(\mathrm{P}<0.01)$ who occurred death. In univariate analysis, a decreased HDL-C level was significantly associated with decreased OS (HR, 0.679; 95\% CI, 0.570-0.808, P<0.01; Table 4; Figure 3) 
and remained statistically different in the multivariate analysis that included tumor size, AFP, tumor differentiation, and TNM stage (HR, 0.790; 95\% CI, $0.658-0.948, \mathrm{P}=0.011$; Table 4). Patients with HDL-C levels $\leq 0.88 \mathrm{mmol} / \mathrm{L}$ had a median OS of 31 months. In contrast, patients with HDL-C levels > 0.88 $\mathrm{mmol} / \mathrm{L}$ had a median OS of 61 months. In the univariate analysis, an increased HDL-C level was

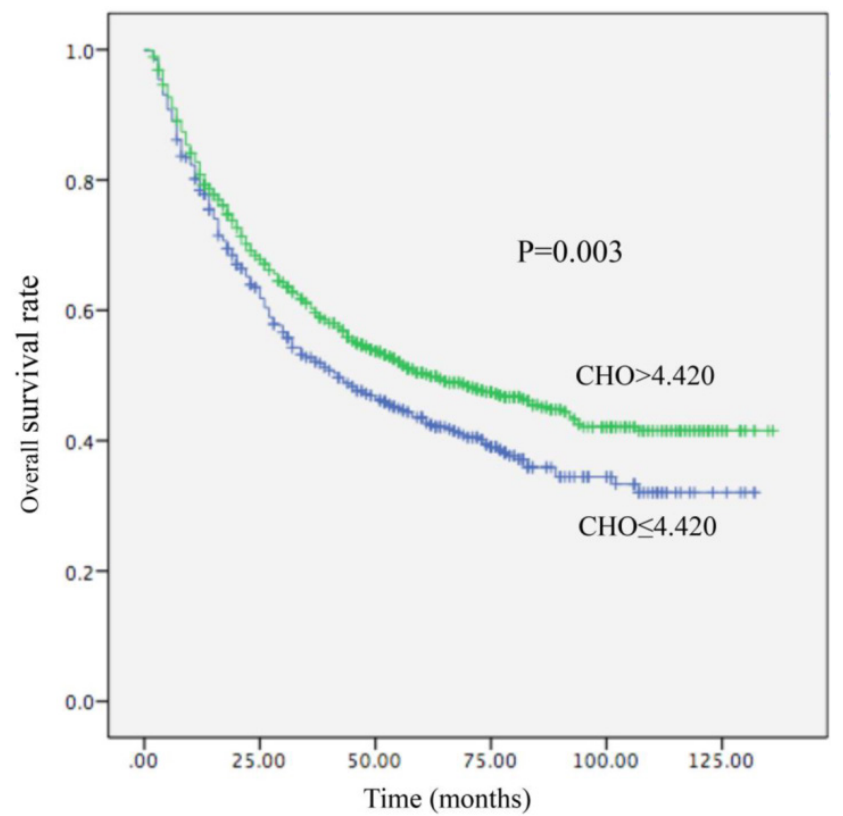

Figure 1. Kaplan-Meier curve for overall survival regarding low vs high $\mathrm{CHO}$ levels $(P=0.003)$.

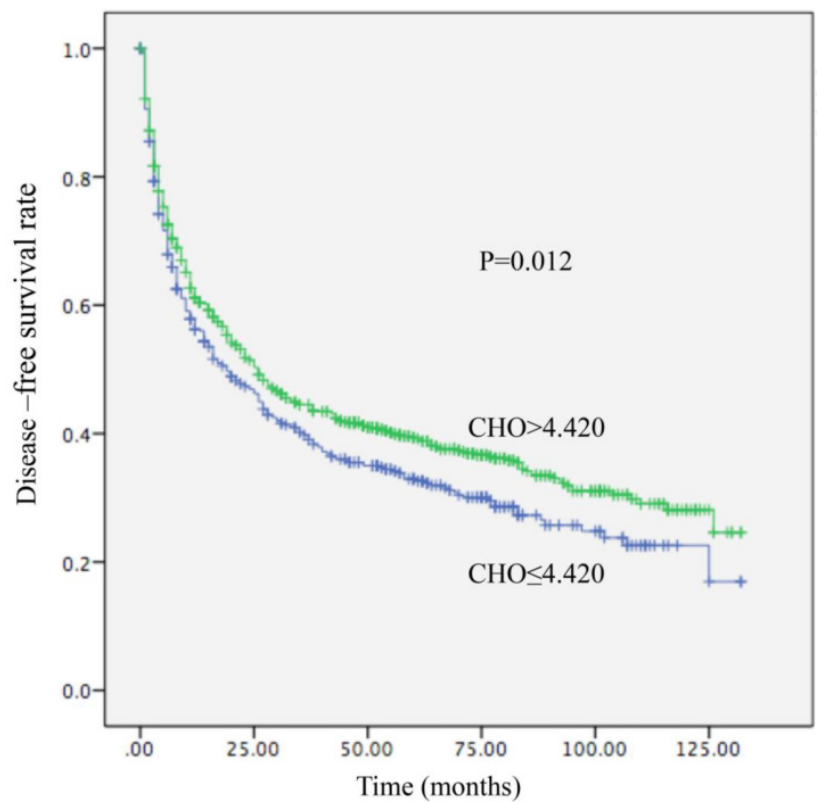

Figure 2. Kaplan-Meier curve for disease-free survival regarding low vs high $\mathrm{CHO}$ levels $(\mathrm{P}=0.012)$. statistically linked with increased DFS (HR, 2.085; 95\% CI, 1.271-3.422, P = 0.002; Table 5; Figure 4). However, in the multivariate analysis, HDL levels were not statistically significant (Table 5). Patients with HDL-C levels $\leq 0.88 \mathrm{mmol} / \mathrm{L}$ presented with a median DFS of 15 months, whereas patients with HDL-C levels $>0.88$ $\mathrm{mmol} / \mathrm{L}$ had a median DFS of 26 months.

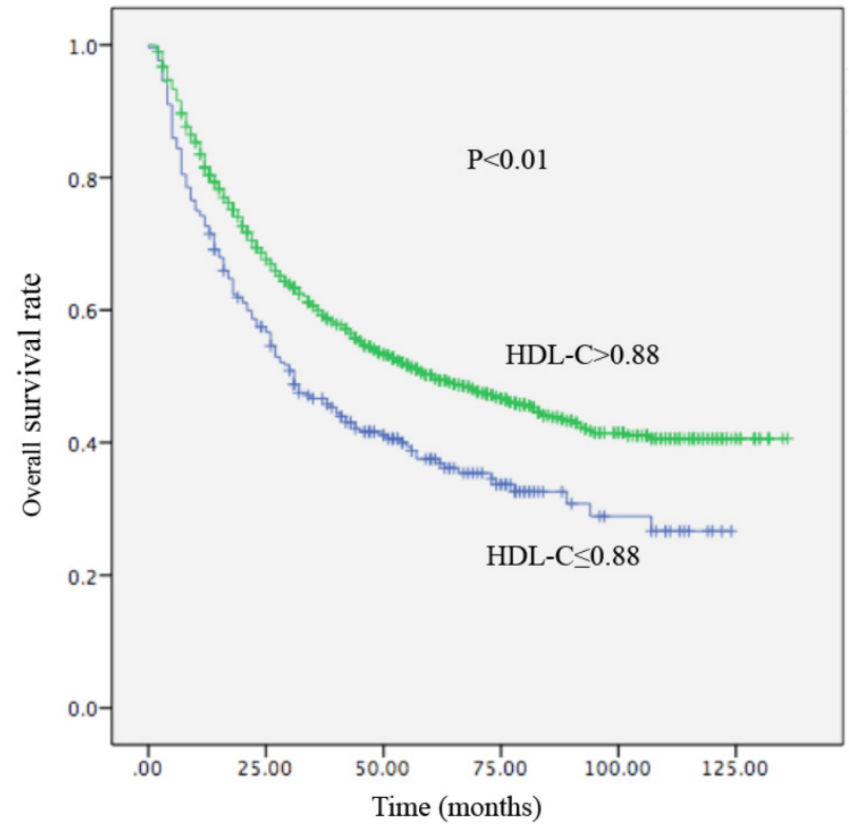

Figure 3. Kaplan-Meier curve for overall survival regarding low vs high HDL-C levels $(P<0.01)$.

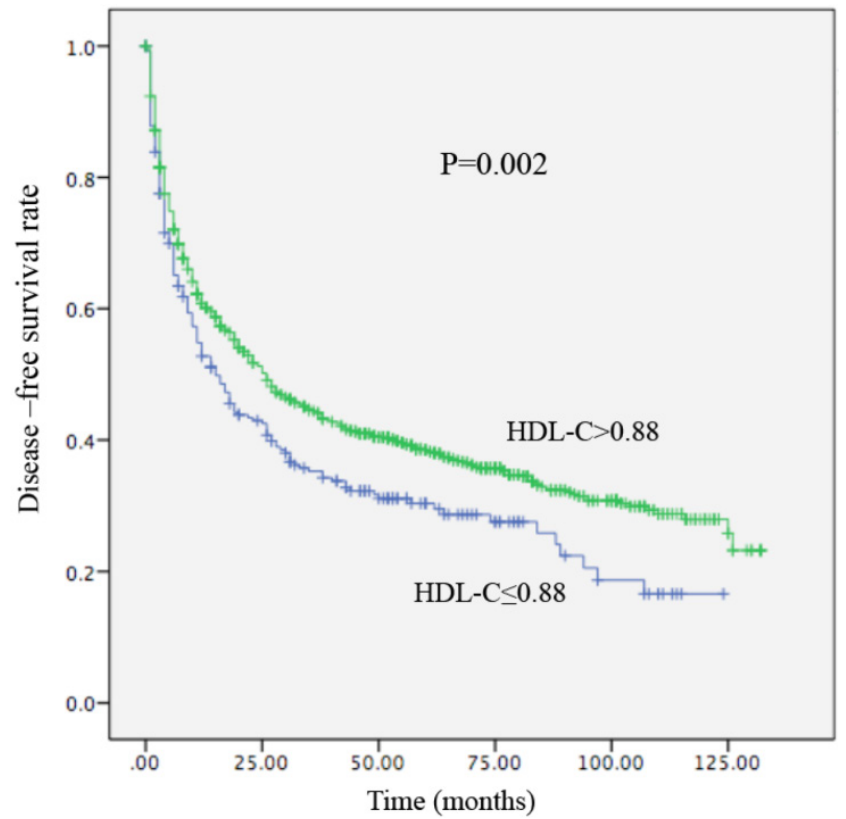

Figure 4. Kaplan-Meier curve for disease-free survival regarding low vs high HDL-C levels $(P=0.002)$. 
Table 5. Univariate and Multivariate Cox Proportional Analysis with Disease-Free-Survival.

\begin{tabular}{|c|c|c|c|c|}
\hline \multirow{2}{*}{ Parameter } & \multicolumn{2}{|c|}{ Univariate Analysis } & \multicolumn{2}{|c|}{ Multivariate Analysis } \\
\hline & $\mathrm{HR}(95 \% \mathrm{CI})$ & $\mathrm{P}$ & $\mathrm{HR}(95 \% \mathrm{CI})$ & $\mathrm{P}$ \\
\hline Age & $1.049(0.920-1.197)$ & 0.476 & & \\
\hline \multicolumn{5}{|l|}{$\leq 50$} \\
\hline \multicolumn{5}{|l|}{$>50$} \\
\hline Gender & $1.158(0.938-1.430)$ & 0.173 & & \\
\hline \multicolumn{5}{|l|}{ Female } \\
\hline \multicolumn{5}{|l|}{ Male } \\
\hline \multicolumn{5}{|l|}{ Tumor size } \\
\hline$\leq 5 \mathrm{~cm}$ & $1.725(1.499-1.985)$ & $<0.001$ & $1.967(1.084-3.567)$ & 0.026 \\
\hline \multicolumn{5}{|l|}{$>5 \mathrm{~cm}$} \\
\hline HBsAg & $0.990(0.813-1.207)$ & 0.924 & & \\
\hline \multicolumn{5}{|l|}{ Negative } \\
\hline \multicolumn{5}{|l|}{ Positive } \\
\hline Cirrhosis & $1.003(0.873-1.151)$ & 0.970 & & \\
\hline \multicolumn{5}{|l|}{$\mathrm{NO}$} \\
\hline \multicolumn{5}{|l|}{ Yes } \\
\hline $\operatorname{AFP}(\mathrm{ng} / \mathrm{ml})$ & $1.435(1.237-1.664)$ & $<0.001$ & $1.288(1.107-1.498)$ & 0.001 \\
\hline \multicolumn{5}{|c|}{ क्ष } \\
\hline \multicolumn{5}{|l|}{$>20$} \\
\hline Tumor number & $1.972(1.700-2.288)$ & $<0.001$ & & \\
\hline \multicolumn{5}{|l|}{ Single } \\
\hline \multicolumn{5}{|l|}{ Multiple } \\
\hline Tumor differentiation & $1.410(1.193-1.665)$ & $<0.001$ & $1.238(1.045-1.466)$ & 0.014 \\
\hline \multicolumn{5}{|c|}{ I-II } \\
\hline \multicolumn{5}{|l|}{ III-IV } \\
\hline TNM stage & $2.324(2.034-2.654)$ & $<0.001$ & $2.023(1.703-2.403)$ & $<0.001$ \\
\hline \multicolumn{5}{|l|}{ I } \\
\hline \multicolumn{5}{|l|}{ II-III } \\
\hline BCLC stage & $1.713(1.487-1.974)$ & $<0.001$ & & \\
\hline \multicolumn{5}{|l|}{$\mathrm{O}-\mathrm{A}$} \\
\hline \multicolumn{5}{|l|}{ B-C } \\
\hline $\mathrm{CHO}(\mathrm{mmol} / \mathrm{L})$ & $0.844(0.737-0.966)$ & 0.012 & $0.850(0.740-0.977)$ & 0.022 \\
\hline \multicolumn{5}{|l|}{$\leq 4.42$} \\
\hline \multicolumn{5}{|l|}{$>4.42$} \\
\hline TG (mmol/L) & $0.964(0.844-1.101)$ & 0.588 & & \\
\hline$\leq 1.06$ & & & & \\
\hline$>1.06$ & & & & \\
\hline LDL (mmol/L) & $0.890(0.780-1.015)$ & 0.082 & & \\
\hline$\leq 3.09$ & & & & \\
\hline$>3.09$ & & & & \\
\hline HDL (mmol/L) & $0.778(0.659-0.918)$ & 0.003 & $0.899(0.758-1.067)$ & 0.222 \\
\hline$\leq 0.88$ & & & & \\
\hline$>0.88$ & & & & \\
\hline
\end{tabular}

\section{Discussion}

Due to the high rate of relapse after HCC resection, the risk factors for tumor relapse are worth studying and could help support the initiation of interventional measures earlier and improve the surveillance to reduce the rate of relapse and improve the quality of survival for patients with HCC [19-22]. Several studies have confirmed that abnormal lipid profiles associated with an increased risk of recurrence and decreased survival in several cancers, including HCC [23-24]. However, the present study enrolled a relatively large amount of Chinese patients to investigate the lipid profiles and HCC prognosis.

Approximately $80 \%$ of endogenous cholesterol is synthesized in the hepatocellular microsomes containing cholesterol synthase [25-26]. In chronic liver diseases and HCC, the metabolism and synthesis of cholesterol are damaged, which lead to a decrease in plasma cholesterol levels [27-28]. In our research, we found that having a lower $\mathrm{CHO}$ level results in a poor prognosis in HCC patients. Additionally, lower cholesterol levels are related to cirrhosis and not to cancer stages. Similar results have been described in patients with gastric cancer [29]. Decreased serum cholesterol concentration was also found in other cancers [30-31], which are probably associated with the increased metabolism of cholesterol by the tumor cells. Additionally, it is reported that the synthesis of cholesterol has been reduced in cancer patients [32], and moderate increase of serum cholesterol levels may be a protective factor on cancer mortality.

In current years, there is increasing evidence that HDL-C may be linked with the tumorigenesis and progression of cancers [33]. In the present study, we investigated the relation between HDL-C and hepatocellular carcinoma, and found that increased pre-operative plasma HDL-C levels were associated with increased DFS and OS after radical surgery.

From previous studies, two possible molecular mechanisms have suggested for the relation between HDL-C and the relapse of HCC and poor survival. One is that HDL-C remove redundant cholesterol from an intracellular pool to maintain normal cell cholesterol homeostasis. It was observed that serum HDL-cholesterol levels were negatively associated with cholesterol levels in the tumor tissues of patients [15]. Due to an increasing consumption and storage of cholesterol within tumor tissues during growth, it is potential to assume that lower HDL levels are linked with the increasing cholesterol metabolism in proliferating tissues.

Another mechanism includes HDL metabolism, which could be regulated by cytokines. Increased levels of HDL have been connected with decreased circulating levels of proinflammatory cytokines, such as interleukin 6(IL-6), IL-1, and tumor necrosis factor (TNF- $\alpha$ ), whereas linked with elevated levels of anti-inflammatory cytokines, for example IL-10 [34]. These proinflammatory cytokines are thought to improve cell proliferation and inhibit apoptosis [35].

Our study indicated that $\mathrm{CHO}$ and HDL-C levels are significantly related with HCC generation and development, and might be helpful in the identification and follow-up of high-risk HCC patients. $\mathrm{CHO}$ and HDL-C levels at diagnosis are considered as prognostic factors for HCC.

\section{Abbreviations}

CHO: cholesterol; TG: triglycerides; HDL-C: high-density lipoprotein -cholesterol; LDL-C: 
low-density lipoprotein-cholesterol; DFS: disease-free survival; OS: overall survival; HCC: hepatocellular carcinoma

\section{Competing interests}

The author(s) declare no competing financial interests.

\section{References}

1. Torre LA, Bray F, Siegel RL, Ferlay J, Lortet-Tieulent J, Jemal A. Global cancer statistics, 2012. CA: a cancer journal for clinicians. 2015; 65: 87-108.

2. Rahbari NN, Mehrabi A, Mollberg NM, Muller SA, Koch M, Buchler MW, et al. Hepatocellular carcinoma: current management and perspectives for the future. Annals of surgery. 2011; 253: 453-69.

3. Stockmann M. Resection of hepatocellular carcinoma in patients without cirrhosis (Br J Surg 2011; 98: 697-703). The British journal of surgery. 2011; 98: 703

4. Muscari F, Foppa B, Carrere N, Kamar N, Peron JM, Suc B. Resection of a transplantable single-nodule hepatocellular carcinoma in Child-Pugh class A cirrhosis: factors affecting survival and recurrence. World journal of surgery. 2011; 35: 1055-62.

5. Zhou L, Rui JA, Wang SB, Chen SG, Ou O, Chi TY, et al. Factors predictive for long-term survival of male patients with hepatocellular carcinoma after curative resection. Journal of surgical oncology. 2007; 95: 298-303

6. Naito S, Imamura H, Tukada A, Matsuyama Y, Yoshimoto J, Sugo H, et al. Postoperative recurrence pattern and prognosis of patients with hepatocellular carcinoma, with particular reference to the hepatitis viral infection status. Liver international : official journal of the International Association for the Study of the Liver. 2014; 34: 802-13.

7. Guo R, Feng X, Xiao S, Yan J, Xia F, Ma K, et al. Short- and long-term outcomes of hepatectomy with or without radiofrequency-assist for the treatment of hepatocellular carcinomas: a retrospective comparative cohort study. Bioscience trends. 2015; 9: 65-72

8. Chuma M, Sakamoto M, Yamazaki K, Ohta T, Ohki M, Asaka M, et al. Expression profiling in multistage hepato carci nogenesis: identification of HSP70 as a molecular marker of early hepatocellular carcinoma. Hepatology. 2003; 37: 198-207.

9. Jiang SS, Weng DS, Wang QJ, Pan K, Zhang YJ, Li YQ, et al. Galectin-3 is associated with a poor prognosis in primary hepatocellular carcinoma. Journal of translational medicine. 2014; 12: 273.

10. Fiorenza AM, Branchi A, Sommariva D. Serum lipoprotein profile in patients with cancer. A comparison with non-cancer subjects. International journal of clinical \& laboratory research. 2000; 30: 141-5.

11. Siemianowicz K, Gminski J, Stajszczyk M, Wojakowski W, Goss M, Machalski $\mathrm{M}$, et al. Serum HDL cholesterol concentration in patients with squamous cell and small cell lung cancer. International journal of molecular medicine. 2000; 6: 307-11.

12. Alexopoulos CG, Blatsios B, Avgerinos A. Serum lipids and lipoprotein disorders in cancer patients. Cancer. 1987; 60: 3065-70.

13. Umeki S. Decreases in serum cholesterol levels in advanced lung cancer. Respiration; international review of thoracic diseases. 1993; 60: 178-81.

14. Moorman PG, Hulka BS, Hiatt RA, Krieger N, Newman B, Vogelman JH, et al. Association between high-density lipoprotein cholesterol and breast cancer varies by menopausal status. Cancer epidemiology, biomarkers \& prevention : a publication of the American Association for Cancer Research, cosponsored by the American Society of Preventive Oncology. 1998; 7: 483-8.

15. Dessi S, Batetta B, Pulisci D, Spano O, Anchisi C, Tessitore L, et al. Cholesterol content in tumor tissues is inversely associated with high-density lipoprotein cholesterol in serum in patients with gastrointestinal cancer. Cancer. 1994; 73: 253-8.

16. Ahaneku JE, Taylor GO, Olubuyide IO, Agbedana EO. Abnormal lipid and lipoprotein patterns in liver cirrhosis with and without hepatocellular carcinoma. JPMA The Journal of the Pakistan Medical Association. 1992; 42: 260-3.

17. Motta M, Giugno I, Ruello P, Pistone G, Di Fazio I, Malaguarnera M. Lipoprotein (a) behaviour in patients with hepatocellular carcinoma. Minerva medica 2001: 92: 301-5.

18. Chen X, Zhou T, Chen M. Meta analysis of the association of cholesterol with pancreatic carcinoma risk. Journal of BUON : official journal of the Balkan Union of Oncology. 2015; 20: 109-13.

19. Nagasue N, Ono T, Yamanoi A, Kohno H, El-Assal ON, Taniura H, et al. Prognostic factors and survival after hepatic resection for hepatocellular carcinoma without cirrhosis. The British journal of surgery. 2001; 88: 515-22.

20. Laurent C, Blanc JF, Nobili S, Sa Cunha A, le Bail B, Bioulac-Sage P, et al. Prognostic factors and longterm survival after hepatic resection for hepatocellular carcinoma originating from noncirrhotic liver. Journal of the American College of Surgeons. 2005; 201: 656-62.

21. Song $P$, Feng $X$, Inagaki $Y$, Song $T$, Zhang $K$, Wang Z, et al. Clinical utility of simultaneous measurement of alpha -fetoprotein and des-gammacarboxy prothrombin for diagnosis of patients with hepatocellular carcinoma in China:
A multi-center case-controlled study of 1,153 subjects. Bioscience trends. 2014; 8: 266-73.

22. Song P, Feng X, Zhang K, Song T, Ma K, Kokudo N, et al. Perspectives on using des-gamma-carboxyprothrombin (DCP) as a serum biomarker: facilitating early detection of hepato cellular carcinoma in China. Hepatobiliary surgery and nutrition. 2013; 2: 227-31.

23. Yamashita $\mathrm{T}$, Honda $\mathrm{M}$, Takatori $\mathrm{H}$, Nishino $\mathrm{R}$, Minato $\mathrm{H}$, Takamura $\mathrm{H}$, et al. Activation of lipogenic pathway correlates with cell proliferation and poor prognosis in hepatocellular carcinoma. Journal of hepatology. 2009; 50: 100-10.

24. Jiang J, Nilsson-Ehle P, Xu N. Influence of liver cancer on lipid and lipoprotein metabolism. Lipids in health and disease. 2006; $5: 4$.

25. Krisans SK. Cell compartmentalization of cholesterol biosynthesis. Annals of the New York Academy of Sciences. 1996; 804: 142-64.

26. Grunler J, Olsson JM, Dallner G. Estimation of dolichol and cholesterol synthesis in microsomes and peroxisomes isolated from rat liver. FEBS letters. 1995; 358: 230-2

27. Cooper ME, Akdeniz A, Hardy KJ. Effects of liver transplantation and resection on lipid parameters: a longitudinal study. The Australian and New Zealand journal of surgery. 1996; 66: 743-6

28. Ooi K, Shiraki K, Sakurai Y, Morishita Y, Nobori T. Clinical significance of abnormal lipoprotein patterns in liver diseases. International journal of molecular medicine. 2005; 15: 655-60.

29. Tomiki Y, Suda S, Tanaka M, Okuzawa A, Matsuda M, Ishibiki Y, et al. Reduced low-density-lipoprotein cholesterol causing low serum cholesterol levels in gastrointestinal cancer: a case control study. Journal of experimental \& clinical cancer research : CR. 2004; 23: 233-40.

30. Simo Camps E, Orti Llaveria A, Sena Ferrer F, Contreras Barbeta E. [Blood cholesterol in patients with cancer]. Anales de medicina interna. 1998; 15: 363-6.

31. Eggens I, Ekstrom TJ, Aberg F. Studies on the biosynthesis of polyisoprenols, cholesterol and ubiquinone in highly differentiated human hepatomas. Journal of experimental pathology. 1990; 71: 219-32.

32. Larking PW. Cancer and low levels of plasma cholesterol: the relevance of cholesterol precursors and products to incidence of cancer. Preventive medicine. 1999; 29: 383-90.

33. Inamdar P, Mehta G. Correlation Between Obesity and High Density Lipoprotein Cholesterol (HDL-C) in Breast Cancer Patients of Southern Rajasthan. Indian journal of surgical oncology. 2011; 2: 118-21.

34. Esteve E, Ricart W, Fernandez-Real JM. Dyslipidemia and inflammation: an evolutionary conserved mechanism. Clinical nutrition. 2005; 24: 16-31.

35. Yvan-Charvet L, Wang N, Tall AR. Role of HDL, ABCA1, and ABCG1 transporters in cholesterol efflux and immune responses. Arteriosclerosis, thrombosis, and vascular biology. 2010; 30: 139-43. 